\title{
PRELIMINARY PHEASANT STUDIES
}

\author{
By C. WILLIAM BEEBE, \\ Curator of Birds
}

Three months of the summer of 1912 were spent by the writer in the museums of London, Tring, Paris, Berlin and other cities, studying the pheasant collections of these institutions. The ultimate use of the data is for inclusion in a Monograph which is under preparation, but a number of the more general results seem worthy of immediate publication.

\section{GENERAL CLASSIFICATION.}

Not until my studies of the Pheasants are completed do I feel it desirable to discuss the relationship of these birds to one another in detail. Realizing how artificial and arbitrary have been the previous attempts to find some character which would be of use in separating the major divisions of the family, I made elaborate tabulation of several scores of what seemed characters of significance. These were set down at random as I passed from genus to genus in the course of my researches, and not until the final summing up did I know whether any would prove of taxonomic worth.

A number of them, like the character of the relative length of individual primaries, gave encouragement at first only to be discounted by some wholly unexpected exception. Finally one character alone remained and after careful application to every genus it has been found to present no illogical exceptions, and in its unusual nature to be most suggestive. Before going on to discuss this in greater detail I wish to re-emphasize the method pursued in elucidating this and other taxonomic characters. This was not to lay out specimens of a priori supposedly related groups and then examine them for resemblances; but, as I have said, by a blind tabulation of very many characters 
observed in one genus after another, the succession of genera decided often by mere accessibility of the drawers in which the skins were kept.

For inclusion in the Monograph I had long ago chosen arbitrarily to begin with Ithaginis and passing through the more typical Pheasants and through Gallus and Argusianus, to include Pavo, thus accepting on the whole the latter half of the family Phasianidae as defined by R. Bowdler Sharpe. ${ }^{1}$ Of the twenty-two genera which he lists I admit nineteen and these I have separated into four sub-families by the mode of moult of the rectrices.

From the very first day of my two years' field work among the wild pheasants, I made strenuous efforts to assemble a collection of immature, and of moulting adult birds, rather than the fully feathered adults which comprise most museum collections. In this I was successful in the case of all but two genera and when I came to examine carefully the pheasants in various museums I was surprised to find many in actual moult, although outwardly presenting no hint of this condition. So I had no dearth of material of feral birds and in no case had I to depend upon captive specimens, although where I have been able to examine the latter, the conditions have been found to be identical with those observed in the wild shot pheasants.

Not until I had nearly completed my studies did I come across Dr. Bureau's most interesting works on "l'Age des Perdrix." His eleven years of careful and methodical study of the moults of the European Partridge and his equally careful study of the plumage ontogeny of the Red-legged Partridge shows beyond question how regular and reliable is the developmental and seasonal succession of feathers, and that in this respect it is as valuable and trustworthy a character as the color, pattern or form of any dermal structure. When, by the process of elimination, the character of rectrice moult of pheasants alone held my interest, I carefully reviewed the specimens and evidence, and confirmed my results. Nevertheless, let me emphasize, what, in the stimulation of the discovery of what appears to be a new, significant, taxonomic factor, one is apt to forget,

1. A Hand-List of the Genera and Species of Birds, Vol. I. pp. 33-40. 
that the best of such characters is only a make-shift, a mere tentative bridge to tide over both our ignorance and the gaps made by time and space in the succession of organic forms. If tomorrow a more consistent, logical factor be discovered, I shall discard the tail moult without a regret. It seems to serve for the present, as being consistent throughout the family, and more fundamental than some other characters. Quite significant and confirmatory is the fact that, instead of inaugurating wholly new arrangements and juxtapositions of genera, it corresponds in a general way with the classifications, more or less theoretical, of earlier taxonomists.

While one would think that the Tragopans were pheasants rather than partridges, using the former term in the usual loose way, yet when we compare them with other genera on the border line, we find that there is no reason, either of sexual difference in coloration, elaborateness of courtship or other feature which actually sets them apart. Arboricola, Rollulus, Melanoperdix, Ptilopachys, Bambusicola, Galliperdix, Ithaginis,-all have been considered too near the border line, and too much alike, to be separated from the pheasants by any line of distinction. And yet the pheasants as a group, and on the other hand the quail and partridges as a group, are in our minds, very distinct in a general way. So even if Tragopan has to be sacrificed, it has seemed worth while to recognize this sharp line of demarkation, falling between Tragopan and Lophophorus, which the tail moult offers, as at least the best division character yet available, for the marking off of sub-family groups.

In connection with the moult of the tail, Dr. Bureau writes of Perdix cinerea : "Il est bon de faire remarquer que la chute et le remplacement des rectrices se font très régulièrement de dedans en dehors, c'est-a-dire du milieu de la queue vers le bord externe." This I found to be invariably the case both with Ithaginis and Tragopan, that the moult of the tail begins with the central rectrices and proceeds regularly outward. Although I have not been able to examine all of the twenty-odd genera associated with Perdix, such as Caccabis, Francolinus, Arboricola, Coturnix, etc., I am satisfied that this character holds good throughout and would therefore class Ithaginis and Tragopan

1. l'Age des Perdrix, I. p. 70. ("P. cinerea" $=P$. perdix.) 
with the Francolins, European Quail and Partridges as the subfamily Perdicinae.

With no gradual transition, but abruptly as it was unexpected, the student of moult in the group of pheasants, finds in Lophophorus and the succeeding genera, the tail feathers moulted from without, inwards. Just as in Perdix and Ithaginis one finds the outer pair or pairs of juvenile rectrices or, in adults, those of the previous year, persisting for some time after the others have been shed, so in this second sub-family it is the inner pair which is the last to fall. The sub-family Phasianinae, as I define it, includes Lophophorus (+Chalcophasis), Acomus, Lophura (+Diardigallus), Lobiophasis, Crossoptilon, Gennaeus, Catreus, Pucrasia, Syrmaticus (+Calophasis, +Phasianus, partim), Phasianus, Chrysolophus, and Gallus.

When I first examined the moulting rectrices of Argusianus and Polyplectron I was at a loss to explain the apparent confusion, and my new factor seemed about to fall to pieces. The feathers appeared to sprout at random. But nevertheless I tabulated them in the order of their growth in every individual which showed such a condition and when the results were compared I was delighted to find a wholly unexpected agreement, and the third sub-family took form, to which I have given the name Argusianinae. This includes Polyplectron, Chalcurus, Argusianus and Rheinardius. In these birds the moult of the tail begins with the 3rd from the central pair and proceeds outward and inward, the 2nd and 1st pairs falling respectively between the 4 th and 5 th, and the 5 th and 6 th pairs.

Perhaps most distinct from all the other groups, and well placed last in the series of Phasianidae genera, are the Peafowl. Pavo is set apart by many characters, and it is gratifying to find that this isolation is borne out in the moult of the tail, by which we may characterize it Pavoninae. The 2nd pair from the outer falls first, and there follows a regular progression inward, the outer pair being moulted just before the inner ones. This sequence is invariable, both in the ten pairs of rectrices of the cock, and the nine pairs of the peahen.

We may thus sum up the criteria of sequence of rectrice moult as follows, numbering from the central pair of tail- 
feathers outward, and assuming in each case for the sake of simplicity, that there are but six pairs:

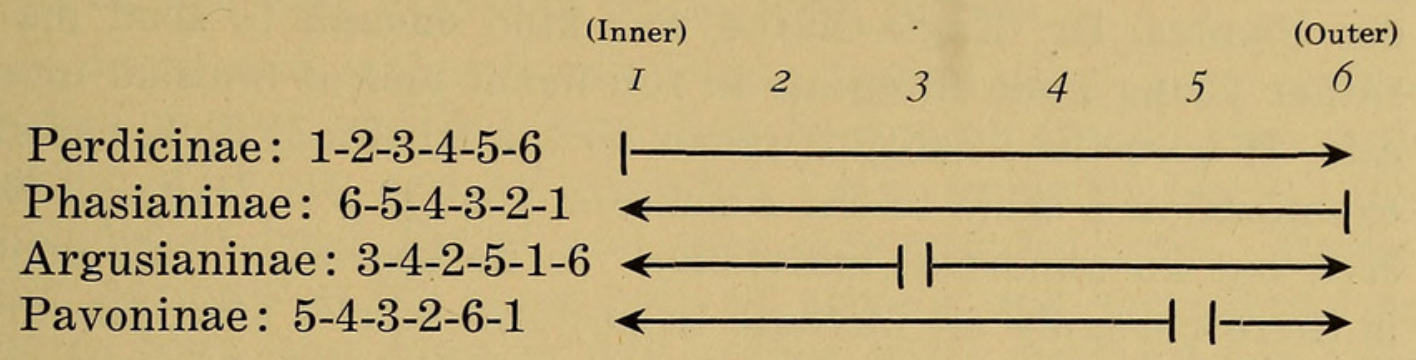

Let me reiterate that I hold this character of tail moult of value only in so far as I have tested it among pheasants. Indeed the more I realize the great number of the factors concerned in evolution, the more I appreciate that any classification must finally be the result of a balanced weighing of equally varied characters. While tail moult may, and it seems to me, does represent a valuable character in dividing the Phasianidae, it may, on the other hand, be wholly useless in connection with any other family of this order.

\section{GENUS ITHAGINIS.}

I have little to add to my recent paper on this genus. ${ }^{1}$ Further study of northern specimens has confirmed the conclusions of Bianchi ${ }^{2}$ so that the present status of members of the genus of Blood Pheasants or, as I shall call them, Blood Partridges, is as follows:

Ithaginis cruentus cruentus (Hardwicke).

Ithaginis cruentus affinis Beebe.

Ithaginis geoffroyi Verreaux.

Ithaginis kuseri Beebe.

Ithaginis sinensis sinensis David.

Ithaginis sinensis michaëlis Bianchi.

Ithaginis sinensis berezowskii Bianchi.

Ithaginis wilsoni Thayer and Bangs.

1. New Blood Pheasants, Zoologica, Vol. I. No. 10.

2. Annuaire du Mus. l'Acad. Imp. Sci., St Petersburg, t. VIII. p. 1. 


\section{ITHAGINIS KUSERI.}

Some time after I had confirmed my 1910 discovery of this species by the mounted specimens in the Museum of the Jardin des Plantes, Dr. Eagle-Clarke was kind enough to send me a rather young male Ithaginis in full moult and of unusual interest. It bore the locality Yunnan on the label and upon careful examination I came to the conclusion that it was Ithaginis kuseri, but an abnormal individual. In no species of this genus is there normally an increase in pectoral scarlet after the first post-juvenile moult, but in two or three individuals I have found an abnormal abortive condition of pigmentation in young birds and this seems another; the degenerate rusty-buff pigment stains on the pectoral plumage being replaced by crimson in the feathers of the succeeding moult.

Since discovering Kuser's Blood Partridge in northern Yunnan, I have been informed by Dr. Annandale of the Indian $\mathrm{Mu}$ seum, Calcutta, that it has been found in the Mishmi Hills by Capt. F. M. Bailey at an elevation of twelve thousand feet, replacing there the Sikhim species. So that it is probable that the species extends in an unbroken range westward from Yunnan to these mountains. This implies a highland connection between the two regions, and also explains the reason for my unexpected extension of the range of Sclater's Impeyan Pheasant (Lophophorus sclateri) from the Mishmi Hills to northwestern Yunnan.

\section{EARLY Plumages of ITHAGINIS.}

The Blood Partridges comprise almost the only genus of those which lie close to the limits of my research, which have not been extensively kept or bred in captivity, so that in their case the changes of plumage have neither been observed nor described. The latter fact is indeed true of a considerable number of more widely known species of the pheasants, but I shall postpone the description of these others, and give only the ontogenetic development of the plumage of the Himalayan and the Chinese Blood Partridge. 


\section{ITHAGINIS CRUENTUS.}

Natal Down.-Chick about a week old; general color scheme -head and neck gray and white, body rufous.

Loral and malar streak, circle around eye, large infraauricular spot and line extending backward around the nape, center of crown and wide nuchal band, brownish-black. Remainder of head, throat and neck pale grizzled gray. Beginning abruptly at the lower neck all around, and backward over entire body, the down is dull rufous with slender black tips, except on the under parts, where the rufous is paler and purer. A central dorsal and two lateral stripes are paler, more buffy.

Seven primaries, eight secondaries and several greater wing-coverts even at this early age are well in evidence, the former having pushed out about $15 \mathrm{~mm}$. beyond their sheaths, the wing measuring $46 \mathrm{~mm}$. The down clinging to the tips of the growing flight-feathers is rarely in a single distal cluster, but more commonly with the separated down filaments supported on the extremities of several distal barbs. The sprouting wing feathers are of unusual breadth, dark brown, mottled irregularly with buff, and tipped with pale buff. Bill from nostril 6 ; tarsus $23 \mathrm{~mm}$.

Juvenile Plumage.-Bird about five weeks old. The dorsal plumage is uniformly of a dull mottled buff and black, each feather with a very conspicuous, terminal, triangular spot of pale buff. The ventral pattern is a wide, buffy-white shaft-stripe bordered irregularly with darker brown, with the margin of the feather pale buff.

As the head and neck are the last to lose the nestling down, so their first contour covering is correspondingly more advanced in color and pattern than the mesoptile body feathers, and hints strongly of the adult plumage. The facial area is but scantily covered with featherlets, the anterior crown is buffy, while the nape and neck show traces of the blue color and white shafts of the adult. The latter is the first certain evidence of the male sex.

The full-grown juvenile tail-feathers are fourteen in number, and measure but $84 \mathrm{~mm}$. in length as compared with 170 in the adult. In shape they are slender, rather pointed and falcate, 
curving slightly outward and noticeably downward. In color they are rufous-buff barred with dark brown. The delayed 7th to 10 th primaries do not finish their growth until the body-moult into adult plumage is well on toward completion.

The post-juvenile moult into the first winter plumage brings the members of this genus into fully adult dress.

\section{ITHAGINIS SINENSIS.}

Natal Down.-When compared with the corresponding chick of Ithaginis cruentus many differences are noticeable. The head and neck with the cold gray, almost white, and black markings are similar, but the down of the entire body, above and below, is very much colder and grayer in sinensis. Instead of warm rufous-buff above, there is only a trace of this on the mantle down. A central back stripe is grizzled grayish-brown and two lateral stripes are pale creamy buff. The breast has a tinge of buff, but this hue is scarcely noticeable on the rest of the ventral surface, the chin, throat and belly being white.

Juvenile Plumage.-This too is unlike the corresponding stage in cruentus. The forehead and crown are not buff but a grayish brown, banded with black and buff on the occiput and nape. The color of the upper surface is distinctly grayer, the terminal pale buff spots thus standing out much more clearly. The black bars on the wing-coverts are also more distinct. The ventral pattern is wholly unlike that of cruentus. There is no trace of the pale buff shaft-stripe, but the feathers are a brownish buff, indistinctly marked with darker and tipped as on the dorsal plumage with a pale buff shaft-spot. This is especially distinct on the breast and upper belly, the feathers posteriorly becoming very loosely vaned, all distinct characters being lost.

\section{Genus TRAGOPAN.}

Unlike Blood Partridges, the Tragopans do not acquire the adult plumage until the second autumn. Many wholly unsupported statements have been made concerning the early plumages and moults of these birds, the general impression being that the change from the juvenile to the first year plumage, and from this to the adult dress is a gradual process; if not by a 
gradual change of color within the feathers themselves, at least by a slow replacing of feathers throughout many months. One finds abundant evidence of this belief, even from collectors' notes on labels, such statements as "young bird in moult" being applied to specimens on purely superficial circumstantial evidence of color and pattern, in cases where there was not a growing feather in the entire plumage.

In this genus and in Lophophorus and others, the cause for this error is easily found. The head and neck of the chick remain clothed in down long after the contour feathers of the body have appeared. When at last the anterior plumage replaces the down, it grows very rapidly, but in the space of a few weeks the pigment secretions have undergone radical changes and instead of the feminine browns and grays of the juvenile body plumage, the young male usually shows a particolored head and neck, differing very much individually, but usually intermediate in color and pattern between juvenile and adult. Thus the superficial impression conveyed during the succeeding twelve months is of a bird in partial moult. This is heightened by adventitious feathers which appear here and there on the body, perhaps a single feather of glowing metallic emerald set off by the surrounding dull brown. For so rapid are the anabolic changes which alter the internal secretions, that within seventy to ninety days after a purely juvenile feather has finished its growth, if it be accidentally pulled out, it will be replaced by a fully adult one. After the second winter's fully adult plumage has been acquired, this incongruity in pattern and pigment is of course no longer apparent.

Without going at present further into details, the sequence of plumages of a bird such as a male Tragopan satyra is most interesting and suggestive.

We find

(a) A down plumage of definite regional patterns.

(b) A juvenile plumage of definitely patterned feathers.

(c) A first winter's plumage of very generalized, femalelike coloration.

(d) An adult plumage exceedingly specialized both as to region and feather, color and pattern. 
KEy TO FEMALE TRAGOPANS.

This rather difficult task has been attempted several times, perhaps most successfully by Prof. Ghigi. ${ }^{1}$ Even this, however, fails when the variations of the ocelli on the plumage of several scores of females are taken into account. I offer the following as a substitute:

A. Dorsal plumage streaked with white.

a Gray dominant on ventral plumage. melanocephalus

b White or buff dominant on ventral plumage. caboti

B. Dorsal plumage not streaked with white.

c Bend of wing not orange rufous. temmincki

d Bend of wing rich orange rufous. $a^{\prime}$ General tone olive; black ocelli dominant on dorsal plumage blythi

b' General tone cream-buff ; black ocelli not dominant on dorsal plumage satyra

\section{CHALCOPHASIS VS. LOPHOPHORUS.}

However much we realize the impossibility of giving equal weight to corresponding taxonomic characters when dealing with families and orders, we should certainly be able to give to the genera in any one sub-family or family a more equally correlated value. I can find no grounds for the separation of the species sclateri from the genus Lophophorus. When we begin to separate individual species in the genera of Phasianinae we soon get into trouble. If we admit Chalcophasis we must split Gallus into three genera, as Gallus gallus, sonnerati and varius exhibit as great differences among themselves as exist between impeyanus and sclateri. Neither of these changes is desirable or necessary. L. sclateri is worthy at most, of only sub-generic distinction.

\section{GENUS LOPHOPHORUS.}

Careful study and comparison of many scores of specimens of this genus prove conclusively that the following are the only valid forms:

1. Studi sul genere Tragopan Cuvier. Memorie della R. Accademia delle Scienze dell' Istituto di Bologna. Serie V. Tomo X. p. 14. 
Lophophorus impeyanus (Latham).

Lophophorus lhuysii Verreaux and St. Hilaire.

Lophophorus sclateri Jerdon.

As synonyms of $L$. impeyanus I class refulgens, chambanus, mantoui and obscurus. In regard to the much-discussed question of impeyanus vs. refulgens and chambanus, aroused by Latham's black-backed monaul, ${ }^{1}$ it is surprising that the attention of the opposing factions has been confined solely to the descriptions and plates in the earlier works of this author. Latham himself settles all doubts on this question in his General History of Birds ${ }^{2}$ where he says: "In the drawing of Lord Mountnorris, is one of the male, with a large patch of white in the middle of the back, which I have not seen in any other representation of this singularly beautiful species."

So the assumption ${ }^{3}$ is correct that Latham was describing and picturing a black-backed individual, but the acceptance of the several black-backed male birds from Chamba as a distinct species is an error. Examination of all the known specimens show as great a variability inter se as the difference between them and normal male impeyanus. This is evident from the following tabulation of the characters supposed to be diagnostic of the black-backed birds:

"Under-parts entirely glossed with metallic golden-green."

This gloss may be

(a) Typically like the above description.

(b) Confined to the breast and irregularly down one side.

(c) Confined to the throat and upper breast.

"Upper tail-coverts chestnut, tipped with golden-green."

(a) Typically like above description.

(b) An excess of green with a little basal rufous.

(c) As in normal impeyanus.

"Lower back golden-green."

This whole area is decidedly abnormal, as the metallic tips are so very small that they are completely separated and dominated by the loose, fluffy basal down, giving the appearance of half the normal number of feathers of this area having been lost. No such scanty, abortive metallic

1. Latham, Gen. Syn. Suppl. I. 1787 , p. 208 , pl. 114. id. Index Orn. II. 1790 , p. 632 .

2. Gen. His. Vol. VIII. 1823, pp. 210-11.

3. Grant, Cat. Birds Brit. Mus. XXII. p. 280. 
coloring occurs on any normal plumage of which I have knowledge. In typical, white-backed individuals a small amount of metallic color sometimes persists on all the white feathers.

In the presence or absence of the copper collar and the extent of the green mantle there is as great variation as in the above mentioned characters.

When in Garhwal and Kashmir I did everything in my power to learn something of the black-backed Monauls, but of two men who had seen them, one had nothing of interest to relate while the other stated that the bird was feeding with several white-backed individuals. No female has ever been found, and chambanus is unquestionably a mutation, sport or abnormal variation as one may choose to call it.

The so-called mantoui and obscurus are of the same nature, no two individuals corresponding exactly to the types, while some show startling variations such as glossy, greenish-black tail-feathers.

It was interesting to find that Lophophorus, according to my classification, has much closer affinities with the true pheasants and Pavo than with Tragopan and the Perdix group. Beside the moult of the tail-feathers, other characters serve to strengthen this bond.

\section{DIARDIGALLUS VS. LOPHURA.}

This case is similar to that of Chalcophasis and Lophophor$u s$, and I can find no character which warrants the generic separation of diardi from Lophura.

\section{GENUS LOPHURA.}

Although the species of this genus do not show any greater variation from the normal than many of the other pheasants, yet atypical individuals have caused great confusion. After careful comparison of all the specimens I could find in the museums of the Far East, of Europe and of America, together with those I was able to collect, I can find no sufficient grounds for separating the Sumatran from the Malayan birds, nor of recognizing 
the single aberrant captive specimen from an unknown locality, now in the Leyden Museum, as distinct from the Bornean Crestless Fireback.

If, on the other hand, such characters as have been utilized in the separation of these two forms are recognized as valid, then I should logically be compelled to distinguish three or four other "species" based on equally variable and, it seems to me, insufficient characters. I have in mind, one male bird with half the mantle of clear chestnut, and another full-grown male with the central rectrices half chestnut, instead of pure white, both wild shot birds. It is wholly impossible to separate the Sumatran birds on the ground that the shaft-stripes of the side and flank feathers are predominately buffy or chestnut rather than white. Over fifty per cent. of the Malayan birds show considerable chestnut on these feathers, and an adult male sent to me in the flesh from Johore to the Raffles Museum, Singapore, exhibited a greater amount of chestnut-red flank markings than I have seen on any Sumatran bird. Such being the case, I see no logical possibility of distinguishing more than a single species of this northern Crested Fireback. As to sumatrana as defined by Buttikofer, ${ }^{1}$ the variation inter se of the five male specimens which he lists is such as to give but slight value to the status of this form. I have seen at least a half dozen adult specimens in the museums of the East and elsewhere, which show as much variation in the chestnut and white of the rectrices and the amount of red on the flanks as in the above mentioned five birds. As these specimens were divided between Sumatra and Pahang, I see no course open but to consider them as aberrant variations of rufa in the direction of ignita.

\section{LOBIOPHASIS BULWERI.}

The sequence of plumage of this splendid Bornean bird, the White-tailed Wattled Pheasant, has heretofore been rather misunderstood. The fully adult plumage is acquired at the third annual moult.

The downy chick moults into a juvenile plumage of rufous brown, finely vermiculated with black. This stage is especially characterized by the rich golden rufous of the tips of the wing-

1. Notes from Leyden Museum, XVII. 1895, p. 177. 
coverts, many of which have a very distinct black, oval ocellus on each web, framed in the golden space. The tail-feathers are dark chestnut, slender and pointed.

The post-juvenile moult into the first year plumage initiates but little change in general appearance, the rufous being richer and many of the feathers having dark tips, while about the neck, except on the nape, is a more or less distinct, wine-colored collar. The rectrices are broader and longer and there are twelve pairs of tail feathers in this plumage. At the succeeding moult, that of the second year, the body plumage of the male becomes very like that of the adult, the chief difference being in the less development of the concave, terminal band of shining blue. As a result of this the crimson of the breast is very pronounced. The rectrices, now as many as thirty-two in number, are rich rufous and very broad.

A few weeks after this moult is completed, if a tail-feather be accidentally pulled out, the one which replaces it will be pure white, but in size will approximate the rufous feathers on either side. Thus while the normal rufous outer tail-feather of this plumage is about $117 \mathrm{~mm}$. in length, and the corresponding white feather of a fully adult bird 218, an adventitious white feather appearing a short time after the previous moult will be intermediate between the two. In this case the pigmental maturing long antedates the change in size, and thus is avoided the danger which a single, long, white projecting feather might bring down upon the immature bird. Strange to say, much of the rachis of such an adventitious tail-feather is quite as bare as in the adult, the factor of structure being again distinct from that of size.

In the adult bird, while the white of the tail is uniform and complete, on the wing feathers this is as yet in process of development. Some individuals show hardly a trace of the white color, but in the richest plumaged birds as many as nine of the primaries will be white, chiefly on the basal half or third.

\section{Genus CROSSOPTILON.}

Of the five usually recognized species of this genus I can accept but three, and indeed I am not wholly satisfied that two 
of these are of more than sub-specific rank, making but two full species.

Crossoptilon mantchuricum Swinhoe.

Crossoptilon auritum (Pallas).

Crossoptilon tibetanum (Hodgson).

A review of the specimens of the two latter species in many museums shows that all the birds from the eastern part of the range are the normal blue-gray auritum, while those from the western part, in Tibet, are typically snow-white tibetanum. In intermediate localities have been found not only typical specimens of each, but also many parti-colored birds to some of which has been given specific rank. These are, in my opinion, examples of that very unusual phenomenon in nature,--hybridism, between the two very distinctly colored forms. No other explanation seems open.

As regards harmoni, all recent describers of the type have merely copied an earlier description and have perpetuated several errors. Such as omitting to mention the posterior extension of white on the throat and the white on the center of the belly. These and other characters are all found combined in various ways and degrees of development in other individuals collected in different parts of Tibet. For example, in the Jardin des Plantes Museum there is a bird, typically harmoni in all respects except that the whole abdomen from the lower breast downward is white and the outer six pairs of rectrices have a great deal of pure white. These feathers number only twenty, and a very careful examination of the root of the tail showed that none had been lost. In view of the observations which follow there is no reason to credit the type specimen of harmoni with having originally had more than twenty-two, or even twenty rectrices.

Crossoptilon leucurum has been separated from tibetanum on account of the presence of white in the tail feathers, but the fact that no two individuals exhibit the same amount of this color, or even show it symmetrically distributed on the right or left feathers, wholly discredits this character as of taxonomic importance. Indeed Hodgson's original type of tibetanum shows white on all the six outer pairs of tail feathers. 
To careless examination and description is due much of the confusion existing among the birds of this genus. Instead of having twenty tail feathers, the majority of the leucurum-like individuals have twenty-two. The male type possesses twenty at present, but a glance at the skin surface over the pygostyle shows two gaping holes from which the other pair has been pulled, while the female type still has twenty-one, the outer left rectrice having been lost.

In the latter bird the rectrice white is present only as a small spot on the outer tail-feathers, but increases rapidly until it dominates the next to the central pair. In another specimen the reverse arrangement is found. In two leucurum-like birds with very little white, there are only twenty as the full complement of tail feathers. And so, to be logical we must stretch the description of harmoni and of leucurum to include a multitude of variations, or make new species of almost every individual, or, to follow the only reasonable course of action, both must be sunk as synonyms of one or the other species. Hybridism seems the only explanation of such variation and asymmetry.

The variation in number of tail feathers in Crossoptilon is of interest. In tibetanum there are twenty, and all with vanes quite solid and normal in structure. The whiter leucurum-like birds show no change, but in most of those individuals which approach harmoni and auritum, an extra central pair of highly disintegrated feathers appears, above the others, suggesting, from their position, derivation from the upper tail-coverts. In auritum still another pair is present, making twenty-four in all, this additional pair also being central, superior, and much disintegrated. So the specialization is definite as to position. In more than one bird, which in color from beak to tail is typical auritum, I have found after careful macro- and microscopical examination only twenty-two rectrices; none having been lost accidentally, but one of the central pairs being congenitally absent. These birds were unquestionably hybrids with the lessened number of rectrices as the sole indication of their mixed blood.

In the rather isolated, more generalized, brown mantchuricum, twenty-two is the normal number, and here we find but a 
single pair of central, superior, disintegrated tail feathers, showing that the locus of specialization is the same as in the other species.

In the presence or absence of certain rectrices in these birds we encounter another of those unexpected correlations which meets the student of avian evolution at every step. As regards color there is no doubt but that the snow-white tibetanum birds are by far the more specialized. White is always an extreme achievement in pigment radiation or rather elimination, and their colored young show how recently the adult hue has been acquired. But on the other hand, the greater number of four and twenty tail feathers in the blue-gray auritum is in its way, as extreme a specialization-excelled in the family Phasianidae only by the adult Lobiophasis. Thus the complexity of evolution is forever being impressed upon us-specialization correlated with generalization and vice versa in closely related organisms. Only by the sum total-the balance after the intricate addition and subtraction of all its character units, and even then only by visualizing the genealogy in three planes of space-can we ever hope successfully to orient any species in relation to its predecessors and contemporaries.

\section{GENUS GENNAEUS.}

Along the southern slopes of the Himalayas as well as in Burma, Yunnan, China and elsewhere I obtained an unusually complete collection of these interesting and puzzling birds, and especially a series of immature and moulting individuals, some of which prove beyond question that hybridization has had much to do with the excessive variation, which has given cause for the making of almost forty species.

Unfortunately I was obliged to postpone my desire to examine the Oates' collection of Gennaeus in the British Museum, which contains fourteen or fifteen types. Published descriptions of these birds are, on the whole, so meagre as to lesser details, and based in many instances on such exceedingly superficial diagnosis that I do not feel justified in publishing a summary of my observations until such time as the accessibility of the types to visiting ornithologists will provide data on which to base definite and final conclusions. 


\section{GENUS PUCRASIA.}

The Koklass Pheasants seem to exhibit many difficult problems. The intricate colors and patterns of their plumage, the individual variation, and the wide and irregular distribution, all make toward confusion at first thought. In reality, however, when we eliminate the useless characters and correct the errors due to hasty species diagnoses, the genus proves to be one of the most interesting and suggestive of all the Phasianinae. Its various forms reveal one of the rarest phenomena in naturea wide-spread series of delicate gradation, and increasing complexity within a single, closely related group of living creatures. There is no room for doubt but that we can trace the exact route which these birds have taken in past years, starting in Garhwal in the western Himalayas and after a long trek northward, eastward and southward, reaching the seacoast in southeastern China.

I recognize the following three species, comprising ten subspecies of this genus:

Pucrasia macrolopha macrolopha (Less.).

Pucrasia macrolopha biddulphi Marsh.

Pucrasia macrolopha castanea Gould.

Pucrasia macrolopha nipalensis Gould.

Pucrasia xanthospila xanthospila Gray

Pucrasia xanthospila ruficollis David and Oustalet.

Pucrasia xanthospila meyeri Madarasz.

Pucrasia xanthospila joretiana Courtois.

Pucrasia darwini darwini Swinhoe.

Pucrasia darwini styani Grant.

The character upon which I place most importance in the definition of full species in the genus Pucrasia is the increasing complexity of the mantle pattern (extending also to other parts of the plumage) in the males. In macrolopha, xanthospila and darwini this pattern may correctly be described as single, double and quadruple respectively.

In macrolopha the mantle feathers are cold ashy gray with a wide, black shaft-stripe extending almost to the tip. Careful examination of the base of the feathers reveals the fact that 
a white wedge has been driven some distance up the shaft, but this anlage of a splitting of the black stripe is not visible when the feathers are in place.

In xanthospila and its congeners the central wedge of light color has spread up the entire vane and there are two lines of black instead of one.

In darwini the third and most complex development of the pattern is found. Two additional lateral white wedges have appeared, splitting the two longitudinal black lines into fourthe quadruple pattern. Thus the devolopment and geographical distribution must have been from macrolopha, through xanthospila to darwini.

\section{PUCRASIA MACROLOPHA MACROLOPHA AND ITS ALLIES.}

The Koklass Pheasants from Kumaon and Garhwal (P. macrolopha macrolopha) are undoubtedly the most generalized of the entire genus. Going westward and eastward from this point we find the birds becoming more and more specialized in color but not in pattern, until in Afghanistan in the one direction and central Nepal in the other, the two extremes are encountered. In fact macrolopha is, without question, the center of radius for all the other geographically adjacent members of the genus. For example in a large series of specimens, all from central Kumaon and Garhwal, we find strong hints of the following:

Chestnut darkening ventrally and encroaching on mantle, typical macrolopha back-toward biddulphi and castanea.

Chestnut darkening ventrally and encroaching on mantle, dark back-toward nipalensis.

Distinctly yellow mantle-toward xanthospila.

In many specimens there are distinct shaft-streaks of chestnut not only on the high neck but even low down on the mantle and as we go westward the birds merge into biddulphi. On many Koteguhr birds the ventral chestnut is very wide spread and fully as dark as in castanea. The more extreme 
castanea forms vary much among themselves in this character, two which I have seen being exactly intermediate between castanea and buddulphi. Gould's statement that castanea is "altogether a stouter and larger bird than Pucrasia macrolopha" is wholly without foundation, and was based on the superficial appearance of his very much overstuffed type specimens. Careful comparisons show practically no difference in size, and where there is, the slight increase is in favor of macrolopha. There is no alternative but to give only sub-specific rank to these two forms, although even trinomials do not tell the whole truth, as biddulphi lies between castanea and macrolopha. They fully deserve this distinction, however, as the variations are clearly geographical.

East of Kumaon we find the Koklass Pheasants becoming more and more dark over the entire plumage, while the chestnut appears on and spreads over the mantle. Many of the so-called specimens of nipalensis from Jumla, western Nepal, and the vicinity, are indistinguishable from the more dark-mantled macrolopha from Kumaon. No description has ever been given of the extreme nipalensis type; all relate to intermediate specimens, so I offer the following diagnosis of Pucrasia macrolopha nipalensis:

Adult Male.-Head and neck as in macrolopha, except that the crown and the shorter part of the crest is warm rufous buff. The hind neck and mantle are dark chestnut, the black being confined to the tip and two narrow, lateral lines down the center of the webs. On the upper back the chestnut dies out as a narrow shaft-streak. The back is black with scarcely a trace of white edging, but on the lower back a light margin persists and on the rump and upper tail-coverts this increases in width and becomes tinged with buff. The chestnut of the mantle is continued directly on to the scapulars, tertiaries and inner secondaries; on the former as a bright shaft-stripe and on the inner web, increasing and paling posteriorly, until on the inner secondaries it covers most of the feather, as a clouded, but still rich, rufous. It decreases to a shaft-stripe on the succeeding secondaries, and on the primaries covers the narrow outer web with a warm rufous buff. The lesser wing-coverts are jet black, the greater dark brown, uniform for the most 
part, but here and there with an evanescent narrow fringe, white on the lesser, rufous on the greater coverts.

The tail is entirely free from gray or sandy color, and only the shorter upper tail-coverts show even the buffy-white fringe of the rump. The longer ones are similar to the central rectrices, chestnut with a central line of black. The chestnut persists strongly even on the outer feathers, while the narrow white fringe is most pronounced on the outer ones and dies out before it reaches the central feathers.

On the under parts the dark chestnut is developed only to about the same extent as in macrolopha, except of course on the side neck, where it joins that of the mantle. But I have seen individuals of otherwise typical macrolopha, which had more ventral chestnut than any Nepal bird. The sides of the breast and belly show no trace of ashy, but are dull jet black, with, as on the wing-coverts, adventitious hints of whitish fringe. This is wider and more distinct on the flanks. The under tail-coverts are rich light chestnut.

There is not a single character quoted above which may not be found in all conditions of gradation between the extreme here described and the extremely pale form of macrolopha.

It differs from the castanea off-shoot in combining intense melanism with increased erythryism, while castanea shows the latter only on the mantle and ventral surface.

Adult Female.-The females, within much more narrow limits, show as much variation as do the the males, but the extreme reached through a series of gradual steps shows decided erythryism, both on the dorsal and ventral surfaces. The whites of macrolopha become buffs; the buffs of the western form are warm rufous buffs in nipalensis.

\section{PUCRASIA XANTHOSPILA AND ITS ALLIES.}

As we have seen, the Koklass Pheasants of the extreme western Himalayas and of central Nepal develop chestnut mantles. Those of Tibet and of Northern China acquire a less extensive but very distinct yellow dorsal collar. This is foreshadowed in about twenty per cent of macrolopha macrolopha, in 
which a strong yellow buff tinge is present about the side and hind neck. The mantle stripe is doubled as I have already described, and the geographical hiatus of Tibet, in which we know of no intermediates, requires that the northern forms be considered a distinct species.

$P$. xanthospila meyeri may be considered somewhat of a linking form, for while possessing to an extreme degree the double dorsal pattern of xanthospila, it still retains the rufous rectrices of macrolopha.

$P$. xanthospila ruficollis is a well-marked form from Kansu, not to be considered more than a sub-species owing to the great individual variation in both amount and shade of the yellow collar in more typical xanthospila. A third, P. xanthospila joretiana has recently been found with characters tending in the direction of darwini.

Thus we find a second hiatus between forms possessing the double and the quadruple pattern, a specific gap which is apparently real and only partly bridged by joretiana. Hence the birds of southeastern China form the third darwini group, all characterized by the complex dorsal pattern.

In darwini, the yellow mantle is lost, the colors being as in macrolopha, while the oblique black tail-band of xanthospila is broken in both sexes. There is a decided diffusion and weakening of the ventral chestnut, even in the strongest marked birds, which may be taken as the more typical. In a series collected in one locality in Fokien, the greatest variation is found in the presence or absence of this chestnut, and in more than one specimen it is wholly lacking as a recognizable factor in the ventral patterning.

In describing Pucrasia styani from Ichang, Mr. Grant selected a male which differs in no respect from the extreme darwini birds in the British Museum series. What he mentions as a "second male" is an extreme in styani coloration, the chestnut having been eliminated not only as a solid, central, ventral marking, but also from all the rest of the body plumage, making the bird, as a whole, of the clean black and gray type of coloring, which in darwini is found only on the mantle. We thus accord the Ichang birds only sub-specific rank, Pucrasia darwini styani. 


\section{GENUS PHASIANUS.}

My studies of the birds of this genus are not complete and I shall not touch upon them at present except in the following pages with reference to the soemmerringii group.

\section{GENUS SYRMATICUS.}

This genus has heretofore contained but a single species, reevesi. As the result of careful comparative study I have expanded it to include five additional species, as follows:

Syrmaticus reevesi Gray.

Syrmaticus ellioti (Swinh.).

Syrmaticus humiae (Hume).

Syrmaticus burmanicus (Oates).

Syrmaticus mikado (Grant).

Srymaticus soemmerringii soemmerringii (Temm.).

Syrmaticus soemmerringii scintillans (Gould).

Syrmaticus soemmerringii ijimae (Dresser).

A superficial glance at the males of such pheasants as Reeves, Elliots, Mikado and Copper shows a diversity of color which seems to have nothing in common. But in the greatly elongated and narrowed central rectrices and a number of other characters we find that they agree, and differ from the other nearly related genera. In the females also we find real criteria of relationship.

Taking females of these six species and placing them side by side we are at once struck with the great similarity of their rather specialized colors and patterns. Comparison with the corresponding sex of related genera emphasizes this similarity.

The following tabulated characters will serve to illustrate this :

\section{SYRMATICUS FEMALES.}

a-Lateral rectrices always dominantly rufous; with subterminal black and terminal white bands.

$b$-Breast solidly or heavily marked; belly wholly or dominantly white. 
c-Mantle with conspicuous white, arrow shaft-marks, or, soemmerringii a pale shaft line or terminal streak.

$d$-Central one or two pairs of rectrices with very indistinct cross-bars (except mikado), and strikingly unlike the 3rd and other lateral pairs.

Comparing these characters with those of Phasianus for example, we find the lateral rectrices with little or no rufous and barred throughout; the central rectrices not differing from lateral ones and with distinct cross-bars; the breast never decidedly distinct in pigmentation from the rest of the ventral surface; the mantle never with white or pale shaft-streaks.

The disintegrated, hair-like condition of the rump feathers in the males of true Phasianus becomes an important character, diagnostic of the genus when the soemmerringii group is removed. This is wholly absent from the soemmerringii group and Syrmaticus as I define it. As to intra-generic differences; (1) ellioti, humiae, burmanicus and mikado possess sixteen rectrices, while reevesi and soemmerringii have eighteen. In this instance the remarkable resemblance; between the females certainly is a more fundamental and important character than the difference of a pair of tail feathers, when, to quote but a single illustration, we remember that in the genus Gallus, varius possesses one pair of rectrices more than gallus. (2) The extreme difference in color of the males would seem to militate against uniting them in a single genus, until we consider the parallel case of Chrysolophus where the Golden and Amherst males present very diverse patterns and colors. The genus Syrmaticus as I define it seems a logical assemblage of forms, capable certainly of sub-generic division, but on the whole differing in no more important characters than occur in other phasianine genera.

\section{GeNUS GALLUS.}

See note under Chalcophasis, p. 270.

Gallus aeneus, temminckii and violaceus are neither "distinct species" nor "domestic varieties" but first generation hybrids between a wild cock varius and a domestic hen, known to the Javanese as Bekisars. 
Gallus aeneus Cuvier, is one of the hybrids with violet upper plumage, margined with golden yellow; comb with minute teeth, and a small median wattle.

Gallus temminckii Gray, is the red phase of hybrid. All the plumage is margined with golden chestnut; six coarse teeth in comb; well developed median throat wattle and small gular wattles.

Gallus violaceus Kelsall, has the violet gloss dominant, a toothed comb and a good-sized median wattle.

G. stramineicollis is merely a large variety of domestic fowl.

After studying all four species of feral Gallus in their native haunts, as well as many examples of natural and artificial hybridizing, and reviewing the evidence from all points of view, I can find no reason to attribute the ancestry of all varieties of our domestic fowls to other than the Red Junglefowl of India, Gallus gallus (Linnaeus). 


\section{$2 \mathrm{BHL}$ Biodiversity Heritage Library}

Beebe, William. 1914. "Preliminary pheasant studies." Zoologica : scientific contributions of the New York Zoological Society 1(15), 261-285. https://doi.org/10.5962/p.203800.

View This Item Online: $\underline{\text { https://www.biodiversitylibrary.org/item/97326 }}$

DOI: https://doi.org/10.5962/p.203800

Permalink: https://www.biodiversitylibrary.org/partpdf/203800

\section{Holding Institution}

Harvard University, Museum of Comparative Zoology, Ernst Mayr Library

\section{Sponsored by}

Harvard University, Museum of Comparative Zoology, Ernst Mayr Library

\section{Copyright \& Reuse}

Copyright Status: Public domain. The BHL considers that this work is no longer under copyright protection.

This document was created from content at the Biodiversity Heritage Library, the world's largest open access digital library for biodiversity literature and archives. Visit BHL at https://www.biodiversitylibrary.org. 